\title{
Exigências Líquidas de Aminoácidos para Ganho de Peso de Nelores Não-Castrados ${ }^{1}$
}

\section{Fabiano Ferreira da Silva ${ }^{2}$, Sebastião de Campos Valadares Filho ${ }^{3}$, Luís Carlos Vinhas Ítavo ${ }^{4}$, Cristina Mattos Veloso ${ }^{2}$, Rilene Ferreira Diniz Valadares ${ }^{5}$, Paulo Roberto Cecon ${ }^{6}$, Eduardo Henrique Bevitori Kling de Moraes ${ }^{7}$, Pedro Veiga Rodrigues Paulino ${ }^{7}$}

\begin{abstract}
RESUMO - Foram utilizados 40 novilhos Nelore inteiros, com peso vivo médio inicial de $240 \mathrm{~kg}$, sendo quatro novilhos de referência, quatro alimentados para mantença e o restante distribuído em oito tratamentos, com quatro diferentes níveis de concentrado nas dietas $(20 ; 40 ; 60$ e 80\%) e dois níveis de proteína bruta (PB) (15 e 18\%). A fase de recria foi avaliada até $360 \mathrm{~kg}$ de peso vivo e a fase de engorda, até $450 \mathrm{~kg}$ de peso vivo. O volumoso utilizado foi feno de capim Tyfton (Cynodon dactylon). Após o abate, todas as partes do corpo do animal foram pesadas e amostradas. As amostras foram liofilizadas para determinação de matéria seca, pré-desengorduradas com éter e, posteriormente, moídas e determinados os teores de aminoácidos. As exigências líquidas de aminoácidos para ganho de peso foram calculadas segundo o método fatorial, no qual o ganho de proteína foi multiplicado pela composição aminoacídica do corpo vazio. A exigência líquida de aminoácidos para mantença foi estimada. A soma das exigências metabolizável para mantença e ganho compôs a exigência total de aminoácidos metabolizáveis. As exigências líquidas para ganho de aminoácidos diminuíram com o aumento do peso vivo do animal. A exigência total de aminoácidos metabolizáveis, expressos em \% do total de aminoácidos essenciais, não variou muito com o aumento do peso vivo, obtendo-se valores médios de 2,66;15,11;6,09;8,64;9,26;18,48;8,33; 12,01; e 19,41 para metionina, lisina, histidina, fenilalanina, treonina, leucina, isoleucina, valina e arginina, respectivamente.
\end{abstract}

Palavras-chave: aminoácidos, exigências, Nelore

\section{Net Amino Acids Requirements for Weight Gain of Nellore Bulls}

\begin{abstract}
Forty Nellore bulls, with $240 \mathrm{~kg}$ initial live weight (LW), were used. Four were reference bulls, four were fed for maintenance, and the remaining were allotted to eight treatments, with four different concentrate levels in the diets (20,40, 60 and $80 \%$ ) and two levels of crude protein (CP) (15 and 18\%). The growing phase was evaluated up to $360 \mathrm{~kg}$ of LW and the fattening phase, up to $450 \mathrm{~kg}$ of LW. The roughage used was Tyfton bermudagrass hay (Cynodon dactylon). After slaughter, all animal body parts were weighed and sampled. The samples were freeze dried to determine the dry matter, pre-degreased with ether, grinded and the concentrations of amino acids were determined. The net amino acids requirements for gain were calculated according to the factorial method, where the protein gain was multiplied by the empty body amino acids composition. The net amino acids requirements for maintenance were estimated. The sum of the metabolizable requirements for maintenance and gain composed the total metabolizable amino acids requirements. The net amino acids requirements for gain decreased with the increase of the animals live weight. The total metabolizable amino acids requirements, expressed in percentage of the total essential amino acids, did not change a lot as live weight increased, and the mean values were $2.66,15.11,6.09,8.64,9.26,18.48,8.33,12.01$, and 19.41 for methionine, lysine, histidine, phenylalanine, threonine, leucine, isoleucine, valine and arginine, respectively.
\end{abstract}

Key Words: amino acids, needs, Nellore

\section{Introdução}

Nas últimas décadas, considerável atenção foi dada à determinação de requisitos de proteínas para ruminantes, tendo sido proposta uma série de sistemas ou modelos baseados, principalmente, nas frações protéicas degradáveis e não-degradáveis dos alimentos, deixando o campo aberto para a predição de exigências em aminoácidos.

Não há dúvidas de que ruminantes e não-ruminantes devem receber quantidade suficiente de aminoácidos essenciais para atender às necessidades de mantença e produção. No caso de ruminantes, no entanto, a situação é mais complexa, devido às parti-

\footnotetext{
${ }^{1}$ Parte da tese de Doutorado em Zootecnia apresentada pelo primeiro autor à UFV. Financiada pela FAPEMIG.

2 Professor do curso de Zootecnia - UESB - Pc. Primavera, 40 - Itapetinga, BA 45700-000. E.mail: ffsilva@uesb.br; cmveloso@uesb.br

${ }^{3}$ Professor do Departamento de Zootecnia - UFV - Viçosa, MG. E.mail: svcfilho@ufv.br

${ }^{4}$ Professor da Universidade Católica Dom Bosco - Campo Grande, MS. E.mail: itavo@ucdb.br

5 Professor do Departamento de Medicina Veterinária - UFV - Viçosa, MG. E.mail: svcfilho@ufv.br

${ }^{6}$ Professor do Departamento de Informática - UFV - Viçosa, MG.

${ }^{7}$ Mestrando em Zootecnia/UFV - Viçosa, MG. E.mail: eg35439@correio.ufv.br; edukling@bol.com.br
} 
cularidades do metabolismo intermediário, às transformações que os alimentos sofrem durante a fermentação ruminal e às dificuldades de se conhecerem os aminoácidos disponíveis para absorção no duodeno, oriundos de uma mistura de proteínas microbiana, dietética não-degradável no rúmen e endógena (Rodriguez, 1996).

Portanto, conhecendo-se as exigências líquidas de proteína, a composição em aminoácidos dos tecidos e do leite e a eficiência de utilização de cada aminoácidos essenciais, podem-se calcular as exigências diárias de aminoácidos essenciais absorvidos no intestino delgado (Valadares Filho, 1997).

Para atender essas exigências, resta saber qual é a quantidade de aminoácidos absorvidos fornecida pelas fontes protéicas não-degradadas no rúmen e pela proteína microbiana. Considera-se que a proporção de proteína verdadeira na proteína microbiana é de $60 \%$ e a digestibilidade desta no intestino delgado foi assumida como $100 \%$ (Sniffen et al., 1992). Além disso, a quantidade de proteína microbiana sintetizada é dada em função da disponibilidade de carboidratos no rúmen, assumindo-se valor médio de $0,4 \mathrm{~g}$ de $\mathrm{MS}$ microbiana/g de carboidrato degradado no rúmen e que as bactérias possuem, em média, 10\% de compostos nitrogenados (Russell et al., 1992). Então, a quantidade de aminoácidos microbianos absorvidos no intestino delgado pode ser obtida por meio da multiplicação da quantidade de proteína verdadeira microbiana digestível que chega ao intestino delgado pelos seus respectivos teores de aminoácidos.

A quantidade de aminoácidos da proteína não degradada no rúmen (PNDR) disponível para absorção é calculada pelo "Cornell Net Carbohydrate Protein System" (CNCPS), considerando-se as frações $\mathrm{B}_{1}, \mathrm{~B}_{2}$ e $\mathrm{B}_{3}$ da proteína. Inicialmente, a proteína dos alimentos é fracionada em $\mathrm{A}, \mathrm{B}_{1}, \mathrm{~B}_{2}, \mathrm{~B}_{3}$ e $\mathrm{C}$, conforme metodologia descrita por Licitra et al. (1996). A fração A não contribui com aminoácidos e a fração C é considerada não-degradada no rúmen e indisponível para o animal. Segundo Sniffen et al. (1992), o escape percentual das frações $B_{1}, B_{2}$ e $B_{3}$ é dado pela fórmula: escape $=K p / K p+K d$, em que $K p$ é a taxa de passagem do alimento e $\mathrm{Kd}$, a taxa de digestão da respectiva fração. Conhecendo-se as quantidades de cada fração protéica que chega ao intestino delgado, multiplicam-se estas quantidades pelos valores de 100,100 e $80 \%$, respectivamente, para as frações $B_{1}, B_{2}$ e $B_{3}$, obtendo-se, dessa forma, a quantidade de PNDR absorvida no intestino delgado para cada alimento. A quantidade de cada aminoácidos essenciais absorvido no intestino delgado pode ser calculada multiplicando-se a PNDR absorvida no intestino delgado pelos seus respectivos teores de aminoácidos essenciais. O sistema considera que a composição em aminoácidos essenciais da PNDR é similar à da proteína dietética.

Richardson \& Hatfield (1978) tentaram determinar o primeiro, o segundo e o terceiro aminoácidos limitantes, em novilhos em crescimento, canulados no abomaso e recebendo uma dieta purificada essencialmente livre de proteína, mas presumindo ser adequada em nitrogênio total. A excreção urinária de nitrogênio, em novilhos infundidos com L-metionina, foi menor do que em novilhos infundidos com lisina, treonina ou triptofano. A infusão de metionina, lisina e treonina aumentou a retenção de nitrogênio acima daquela obtida, quando metionina e lisina foram infundidas. Metionina, lisina e treonina foram os três primeiros aminoácidos limitantes em bovinos em crescimento, como indicado pelo balanço de nitrogênio, e os três aminoácidos no plasma, quando a proteína microbiana foi essencialmente a única fonte de proteína. Em estudos com carneiros recebendo infusões intragástricas, Storm \& Orskov (1984) demonstraram que a metionina e a lisina limitaram a retenção de nitrogênio, quando a proteína microbiana foi a única fonte de proteína. A arginina e a histidina também pareceram ser potencialmente limitantes neste trabalho. Entretanto, muitos outros aminoácidos essenciais são freqüentemente co-limitantes para o crescimento de novilhos, e a resposta máxima é atingida quando proteínas intactas são fornecidas após o rúmen, comparadas com o fornecimento de um ou dois aminoácidos considerados limitantes (Merchen \& Titgemeyer, 1992).

O objetivo deste experimento foi determinar as exigências líquidas de aminoácidos essenciais para ganho de peso vivo de animais da raça Nelore, nas fases de recria e engorda.

\section{Material e Métodos}

O experimento foi realizado no Departamento de Zootecnia da Universidade Federal de Viçosa, em Viçosa-MG. Foram utilizados 36 novilhos Nelore inteiros, com peso vivo médio inicial de $240 \mathrm{~kg}$. Quatro novilhos foram abatidos após o período de adaptação de 30 dias (grupo referência), servindo de referência nos estudos subseqüentes. Os 32 animais restantes foram pesados e distribuídos em oito trata- 
mentos, com quatro níveis de concentrado $(20 ; 40 ; 60$ e $80 \%)$ e dois níveis de proteína bruta (PB) (15 e $18 \%$ ) nas dietas, na base da matéria seca (MS), em um esquema fatorial 4 x 2 (de concentrado $\mathrm{x}$ níveis de proteína), no delineamento inteiramente casualizado com quatro repetições na fase de recria e duas repetições na fase de engorda. A fase de recria foi avaliada dos 240 aos $360 \mathrm{~kg}$ de peso vivo e a fase de engorda, dos $360 \mathrm{~kg}$ aos $450 \mathrm{~kg}$ de peso vivo. $\mathrm{O}$ volumoso foi composto de feno de capim-Tifton (Cynodon dactylon). As rações foram formuladas de acordo com o NRC (1996). Todas as rações foram formuladas para conter próximo de $32 \%$ de compostos nitrogenados não protéicos. A composição bromatológica das dietas encontra-se na Tabela 1 .

Os alimentos foram fornecidos à vontade, uma vez ao dia, e ajustados de forma a manter sobras em torno de 5 a $10 \%$ do fornecido, com água permanentemente à disposição dos animais. Foi realizada uma pesagem dos animais no início do experimento e, periodicamente, a cada 28 dias. À medida que um animal se aproximava do peso de abate preestabelecido, 360 ou $450 \mathrm{~kg}$ (recria e engorda, respectivamente), era pesado a intervalos menores. Após o abate, o trato gastrintestinal foi pesado, e seu peso foi somado aos dos órgãos e das demais partes do corpo (carcaça, cabeça, couro, cauda, pés e sangue), para determinação do peso de corpo vazio (PCVZ).

A composição de aminoácidos do corpo vazio foi determinada em função das concentrações percentuais destes nas amostras de músculo e em uma amostra composta de vísceras, órgãos, couro, sangue, cauda, cabeça (músculo, gordura e ossos), pés (tendão e ossos) e constituintes separados (gordura e ossos) da seção $\mathrm{HH}$, já liofilizadas, prédesengorduradas e moídas. A seção HH consiste do corte da $9^{\mathrm{a}}, 10^{\mathrm{a}}$ e $11^{\mathrm{a}}$ costelas para estimar a composição física da carcaça, segundo Hankins \& Howe (1946), com as seguintes equações de regressão: Músculo: $\mathrm{Y}=16,08+0,80 \mathrm{X}$; Tecido adiposo: $\mathrm{Y}=3,54$ $+0,80 \mathrm{X}$; Ossos: $\mathrm{Y}=5,52+0,57 \mathrm{X}$; em que $\mathrm{X}$ é a porcentagem dos componentes na seção $\mathrm{HH}$.

O peso utilizado de cada constituinte, na amostra composta, foi proporcional à sua contribuição no total de proteína do corpo vazio, após liofilização, prédesengorduramento e moagem dos mesmos em separado. Aproximadamente $150 \mathrm{mg}$ de proteína da amostra foram hidrolisados com solução de ácido clorídrico $6 \mathrm{~N}$, por 21 horas, a $110^{\circ} \mathrm{C}$. As amostras foram filtradas em filtro-papel Whatman $\mathrm{n}^{0} 1 \mathrm{e} 1 \mathrm{~mL}$ foi transposto para um balão de $50 \mathrm{~mL}$, com posterior secagem em nitrogênio. Completou-se o volume do balão e as amostras foram avaliadas em analisador de aminoácidos HITACHI L8500A.

As exigências líquidas de aminoácidos para ganho de peso foram calculadas segundo o método fatorial proposto por O'Connor et al. (1993), no qual o ganho de proteína (Silva, 2001) foi multiplicado pela composição aminoacídica do corpo vazio. Também foram preditas as quantidades líquidas de aminoácidos retidos no corpo dos animais de cada tratamento, e para todos os tratamentos em conjunto, utilizando-se equações de regressão do logaritmo do conteúdo corporal de aminoácidos, em função do logaritmo do PCVZ, conforme o seguinte modelo:

$$
\mathrm{Y}=\mathrm{a}+\mathrm{bX}+\mathrm{e}
$$

em que: $\mathrm{Y}=$ logaritmo do conteúdo total do aminoácidos $(\mathrm{kg})$ retido no corpo vazio; $\mathrm{a}=$ constante; $\mathrm{b}=$ coeficiente de regressão do logaritmo do conteúdo do aminoácidos, em função do logaritmo do PCVZ; $\mathrm{X}=$ logaritmo do PCVZ; e e = erro aleatório.

Tabela 1 - Teores médios de matéria seca (MS), proteína bruta (PB), extrato etéreo (EE), fibra em detergente neutro (FDN) e nutrientes digestíveis totais (NDT) das dietas experimentais

Table 1 - Average contents of dry matter (DM), crude protein (CP), ether extract (EE), neutral detergent fiber (NDF) and total digestible nutrients (TDN) of the experimental diets

\begin{tabular}{|c|c|c|c|c|c|c|c|c|}
\hline \multirow{2}{*}{$\begin{array}{l}\text { Nível de concentrado }(\% \\
\text { Level of concentrate } \\
\text { Teor de } \mathrm{PB} \\
\text { CP content }\end{array}$} & \multicolumn{2}{|c|}{20} & \multicolumn{2}{|c|}{40} & \multicolumn{2}{|c|}{60} & \multicolumn{2}{|c|}{80} \\
\hline & 15 & 18 & 15 & 18 & 15 & 18 & 15 & 18 \\
\hline $\mathrm{MS}(D M) \%$ & 88,21 & 88,28 & 88,05 & 88,09 & 87,79 & 87,92 & 87,58 & 87,67 \\
\hline $\mathrm{PB}(C P)^{1}$ & 15,67 & 18,85 & 15,10 & 17,63 & 15,11 & 18,26 & 14,52 & 17,11 \\
\hline $\mathrm{EE}^{1}$ & 2,30 & 2,05 & 3,03 & 1,76 & 2,46 & 2,13 & 1,95 & 1,93 \\
\hline FDN $(N D F)^{1,2}$ & 62,37 & 60,60 & 48,62 & 46,46 & 37,90 & 34,62 & 25,94 & 19,65 \\
\hline $\operatorname{NDT}(N D T)^{1}$ & 73,80 & 73,16 & 77,73 & 79,33 & 79,61 & 81,46 & 81,94 & 78,39 \\
\hline
\end{tabular}

$1 \%$ na matéria seca (\% in dry matter).

${ }^{2}$ FDN corrigida para cinzas e proteína (NDF corrected for ash and protein). 
Para cada tratamento, as equações foram construídas adicionando-se os valores relativos aos dos animais referência.

Derivando-se as equações de predição do conteúdo corporal de aminoácidos, em função do logaritmo do PCVZ, foram obtidas as equações de predição das exigências líquidas de aminoácidos para ganho de $1 \mathrm{~kg}$ de PCVZ, do tipo:

$$
\mathrm{Y}^{\prime}=\text { b. } 10^{\mathrm{a}} \cdot \mathrm{X}^{\mathrm{b}-1}
$$

em que: $Y^{\prime}=$ exigência líquida do aminoácido; a e b = intercepto e coeficiente de regressão, respectivamente, das equações de predição dos conteúdos corporais de aminoácidos; e X = PCVZ (kg).

As comparações entre os parâmetros das equações de regressão avaliados para cada tratamento foram realizadas, de acordo com a metodologia recomendada por Regazzi (1996), para testar identidade de modelos.

As exigências líquidas de aminoácidos para mantença foram estimadas a partir da estimativa da proteína bruta endógena basal $\left(\mathrm{PBEB}=2,1875 * \mathrm{PV}^{0,75}\right.$; AFRC, 1993) e da proteína bruta de descamação $\left(\mathrm{PBD}=0,1125^{*} \mathrm{PV}^{0,75}\right.$; AFRC, 1993), multiplicadas pela composição aminoacídica do corpo vazio, obtida neste experimento, e da queratina (Block \& Bolling, 1951, citados por O'Connor et al., 1993), respectivamente, conforme apresentado na Tabela 2. Os aminoácidos metabolizáveis foram calculados utilizando o fator de eficiência (FE) dos aminoácidos para ganho, $\mathrm{FE}=0,83-(0,00114 * \mathrm{PCVZ})$, segundo Ainslie et al. (1993), e, para mantença, segundo os valores descritos por Evans \& Patterson (1985). A soma das exigências metabolizáveis para mantença e ganho compôs a exigência total de aminoácidos metabolizáveis. Entre os aminoácidos essenciais, não foi analisado o triptofano, devido a dificuldades de análise. Para os valores de metionina, utilizou-se o valor médio do corpo vazio de três experimentos sumarizados por Ainslie et al. (1993), devido a falhas na análise deste aminoácido.

As determinações de matéria seca (MS), compostos nitrogenados totais, extrato etéreo (EE) e fibra em detergente neutro (FDN) foram feitas conforme técnicas descritas por Silva (1990). Os teores de nutrientes digestíveis totais (NDT) foram obtidos do experimento de Ítavo (2001).

Tabela 2 - Composição de aminoácidos dos músculos, conjunto (sangue, couro, órgãos, vísceras, ossos e gordura), todos os tecidos do corpo vazio, de bovinos Nelore e da queratina (g/100 g de proteína)

Table 2 - Amino acids composition of muscles, overall (blood, leather, organs, viscera, bones and fat), for all tissues in the empty body of Nellore and of queratin ( $\mathrm{g} / 100 \mathrm{~g}$ of protein)

\begin{tabular}{|c|c|c|c|c|}
\hline $\begin{array}{l}\text { Aminoácidos* } \\
\text { Amino acids }\end{array}$ & $\begin{array}{l}\text { Músculos } \\
\text { Muscles }\end{array}$ & $\begin{array}{c}\text { Conjunto } \\
\text { Overall }\end{array}$ & $\begin{array}{l}\text { Corpo vazio } \\
\text { Empty body }\end{array}$ & $\begin{array}{c}\text { Queratina }^{1} \\
\text { Queratin }\end{array}$ \\
\hline \multicolumn{5}{|c|}{ Aminoácidos essenciais } \\
\hline $\mathrm{Met}^{2}$ & - & - & 2,00 & 1,00 \\
\hline Lys & 7,56 & 4,84 & 5,91 & 3,20 \\
\hline His & 3,13 & 1,80 & 2,39 & 1,00 \\
\hline Phe & 3,67 & 3,11 & 3,34 & 3,70 \\
\hline Thr & 4,32 & 2,92 & 3,52 & 7,20 \\
\hline Leu & 7,49 & 5,71 & 6,42 & 10,00 \\
\hline Ile & 3,68 & 2,27 & 2,88 & 5,00 \\
\hline Val & 4,11 & 4,23 & 4,18 & 6,00 \\
\hline Arg & 7,14 & 8,00 & 7,59 & 3,80 \\
\hline \multicolumn{5}{|c|}{$\begin{array}{l}\text { Aminoácidos não-essenciais } \\
\text { Non essential amino acids }\end{array}$} \\
\hline Asp & 8,83 & 7,17 & 7,88 & - \\
\hline Ser & 3,94 & 3,90 & 3,91 & - \\
\hline Glu & 15,36 & 11,86 & 13,36 & - \\
\hline Gly & 5,76 & 20,02 & 13,79 & - \\
\hline Ala & 5,97 & 9,20 & 7,78 & - \\
\hline Tyr & 3,09 & 1,66 & 2,29 & - \\
\hline Cys & 1,86 & 0,60 & 1,15 & - \\
\hline
\end{tabular}




\section{Resultados e Discussão}

A composição aminoacídica do corpo vazio (Tabela 2) apresentou-se semelhante aos valores de uma média de três experimentos citados por Ainslie et al. (1993), à exceção da arginina, que apresentaram valores maiores que os citados na literatura.

As exigências líquidas para ganho, em $\mathrm{g} / \mathrm{kg}$ de ganho de peso de corpo vazio (GPCVZ), calculada pelo método fatorial, estão apresentadas na Tabela 3. $\mathrm{Na}$ Tabela 4, encontram-se os parâmetros das equações de regressão do logaritmo dos conteúdos dos aminoácidos no corpo vazio, em função do logaritmo do peso do corpo vazio (PCVZ), obtidos para cada nível de concentrado nas dietas e para todos tratamentos em conjunto. Como o teste de identidade de modelos, aplicado às equações de regressão do logaritmo do conteúdo corporal dos elementos minerais, em função do logaritmo do PCVZ, para os quatro níveis de concentrado na dieta, indicou não haver diferença entre os modelos, foram utilizadas as equações relativas aos dados em conjunto para o cálculo das exigências líquidas para ganho pelo método de equações, conforme demonstrado na Tabela 5 .

As exigências líquidas para ganho de aminoácidos, calculadas pelos dois métodos, apresentaram valores próximos. As exigências líquidas, calculadas pelo método fatorial, diminuíram com o aumento do peso vivo do animal, fato esperado, em função de as exigências serem calculadas com as exigências de proteína líquida para ganho, obtidas por Silva (2001), que apresentaram decréscimo em conseqüência do maior acúmulo de gordura, com o aumento do peso vivo (PV). Já as exigências líquidas calculadas pelo método de equações elevaram-se com o aumento do peso vivo do animal, para alguns aminoácidos (Lys, His, Phe, Thr, Leu, Ile, Asp, Glu, Tyr e Cys) e diminuíram para outros (Val, Arg, Ser, Gly e Ala). Como a literatura (Zinn, 1988, O'Connor et al., 1993, Wilkerson et al., 1993) recomenda o cálculo das exigências de aminoácidos pelo método fatorial, as considerações subseqüentes serão realizadas para os valores obtidos por este método. Todavia, pode-se observar que as exigências líquidas de aminoácidos podem ser calculadas pelo método de equações e, possivelmente, tenha coerência, pois, provavelmente, nem todos os aminoácidos apresentam a mesma tendência de diminuição com o aumento do peso vivo do animal.

A partir da estimativa das exigências líquidas de aminoácidos para mantença, determinaram-se as exi-

Tabela 3 - Exigências líquidas de aminoácidos para ganho (g/kg de GPCVZ), de bovinos Nelore, em função do peso vivo (PV), calculada pelo método fatorial

Table 3 - Net requirements of amino acids for gain ( $\mathrm{g} / \mathrm{kg}$ EBWG) of Nellore bovines, in function of live weight (LW), calculated by the factorial method

\begin{tabular}{|c|c|c|c|c|c|c|}
\hline $\begin{array}{l}\mathrm{PV}(\mathrm{kg}) \\
L W(\mathrm{~kg})\end{array}$ & 200 & 250 & 300 & 350 & 400 & 450 \\
\hline & \multicolumn{6}{|c|}{$\begin{array}{l}\text { Exigência líquida } \\
\text { Net requirements }\end{array}$} \\
\hline Met & 2,33 & 2,75 & 3,15 & 3,54 & 3,91 & 4,27 \\
\hline Lys & 10,82 & 10,64 & 10,49 & 10,36 & 10,26 & 10,17 \\
\hline His & 4,37 & 4,30 & 4,24 & 4,19 & 4,14 & 4,11 \\
\hline Phe & 6,12 & 6,02 & 5,94 & 5,87 & 5,80 & 5,75 \\
\hline Thr & 6,46 & 6,35 & 6,26 & 6,19 & 6,12 & 6,07 \\
\hline Leu & 11,76 & 11,56 & 11,40 & 11,27 & 11,15 & 11,05 \\
\hline Ile & 5,28 & 5,19 & 5,12 & 5,06 & 5,01 & 4,96 \\
\hline $\mathrm{Val}$ & 7,66 & 7,53 & 7,43 & 7,34 & 7,27 & 7,20 \\
\hline Arg & 13,91 & 13,68 & 13,49 & 13,33 & 13,19 & 13,07 \\
\hline Asp & 14,44 & 14,19 & 13,99 & 13,83 & 13,69 & 13,56 \\
\hline Ser & 7,17 & 7,05 & 6,95 & 6,87 & 6,80 & 6,74 \\
\hline Glu & 24,49 & 24,07 & 23,73 & 23,46 & 23,22 & 23,01 \\
\hline Gly & 25,27 & 24,84 & 24,49 & 24,20 & 23,96 & 23,74 \\
\hline Ala & 14,26 & 14,02 & 13,83 & 13,66 & 13,52 & 13,40 \\
\hline Tyr & 4,20 & 4,13 & 4,07 & 4,02 & 3,98 & 3,95 \\
\hline Cys & 2,11 & 2,07 & 2,05 & 2,02 & 2,00 & 1,99 \\
\hline
\end{tabular}

$P C V Z=P V * 0,8975$. 
Tabela 4 - Parâmetros das equações de regressão do logaritmo dos conteúdos de lisina, histidina, fenilalanina, treonina, leucina, isoleucina, valina, arginina, aspartato, serina, glutamato, glicina, alanina, tirosina e cisteína, em kg, no corpo vazio, em função do logaritmo do peso do corpo vazio $(\mathrm{kg})$ de bovinos Nelore, para os diferentes níveis de concentrado (NC) na dieta, e em conjunto (CONJ) e os respectivos coeficientes de determinação $\left(r^{2}\right)$

Table 4 - Parameters of logarithm regression equations of lysine, histidine, phenilalanine, threonine, leucine, isoleucine, valine, arginine, aspartato, serine, glutamato, glicine, alanine, tyrosine and cisteyne contents, in $\mathrm{kg}$, in the empty body, on the empty body weight of Nellore bulls, for the different concentrate levels $(C L)$ in the diet and overall and the respective coefficients of determination $\left(r^{2}\right)$

\begin{tabular}{|c|c|c|c|}
\hline $\begin{array}{l}\mathrm{NC}(\%) \\
L C\end{array}$ & & $\begin{array}{l}\text { Parâmetro } \\
\text { Parameter }\end{array}$ & \\
\hline & $\begin{array}{c}\text { Intercepto (a) } \\
\text { Intercept }\end{array}$ & $\begin{array}{l}\text { Coeficiente (b) } \\
\text { Coefficient }\end{array}$ & $\mathrm{r}^{2}$ \\
\hline & & Lisina $(\mathrm{kg})$ & \\
\hline 20 & $-1,9010$ & 0,9755 & 0,89 \\
\hline 40 & $-2,3177$ & 1,1529 & 0,90 \\
\hline 60 & $-1,9758$ & 1,0074 & 0,90 \\
\hline 80 & $-1,8064$ & 0,9353 & 0,70 \\
\hline CONJ. & $-2,0000$ & 1,0177 & 0,85 \\
\hline Overall & & & \\
\hline & & Histidina (kg) & \\
\hline 20 & $-2,7899$ & 1,1650 & 0,92 \\
\hline 40 & $-3,3922$ & 1,4306 & 0,86 \\
\hline 60 & $-2,7179$ & 1,1353 & 0,78 \\
\hline 80 & $-2,7992$ & 1,1748 & 0,91 \\
\hline CONJ. & $-2,9403$ & 1,2329 & 0,85 \\
\hline Overall & & & \\
\hline & & Fenilalanina (kg) & \\
\hline 20 & $-2,1951$ & 0,9979 & 0,96 \\
\hline 40 & $-2,3441$ & 1,0563 & 0,84 \\
\hline 60 & $-2,1491$ & 0,9770 & 0,94 \\
\hline 80 & $-2,1969$ & 0,9989 & 0,94 \\
\hline CONJ. & $-2,2220$ & 1,0079 & 0,92 \\
\hline Overall & & & \\
\hline & & Treonina (kg) & \\
\hline 20 & $-2,3151$ & 1,0537 & 0,96 \\
\hline 40 & $-2,5115$ & 1,1367 & 0,94 \\
\hline 60 & $-2,1950$ & 1,0015 & 0,87 \\
\hline 80 & $-2,2950$ & 1,0471 & 0,94 \\
\hline CONJ. & $-2,3338$ & 1,0617 & 0,93 \\
\hline Overall & & & \\
\hline & & Leucina (kg) & \\
\hline 20 & $-1,9566$ & 1,0192 & 0,96 \\
\hline 40 & $-1,9809$ & 1,0145 & 0,52 \\
\hline 60 & $-1,8384$ & 0,9699 & 0,88 \\
\hline 80 & $-1,9426$ & 1,0140 & 0,93 \\
\hline CONJ. & $-1,9261$ & 1,0023 & 0,78 \\
\hline Overall & & & \\
\hline & & Isoleucina (kg) & \\
\hline 20 & $-2,3777$ & 1,0436 & 0,93 \\
\hline 40 & $-2,7385$ & 1,2009 & 0,89 \\
\hline 60 & $-2,2072$ & 0,9664 & 0,87 \\
\hline 80 & $-2,2771$ & 0,9998 & 0,89 \\
\hline CONJ. & $-2,4051$ & 1,0548 & 0,88 \\
\hline Overall & & & \\
\hline & & Valina $(\mathrm{kg})$ & \\
\hline 20 & $-1,9259$ & 0,9244 & 0,94 \\
\hline 40 & $-2,2912$ & 1,0860 & 0,76 \\
\hline 60 & $-1,8812$ & 0,9034 & 0,92 \\
\hline 80 & $-1,9012$ & 0,9129 & 0,91 \\
\hline CONJ. & $-2,0056$ & 0,9591 & 0,86 \\
\hline Overall & & & \\
\hline
\end{tabular}


Continuação da Tabela 4 ..

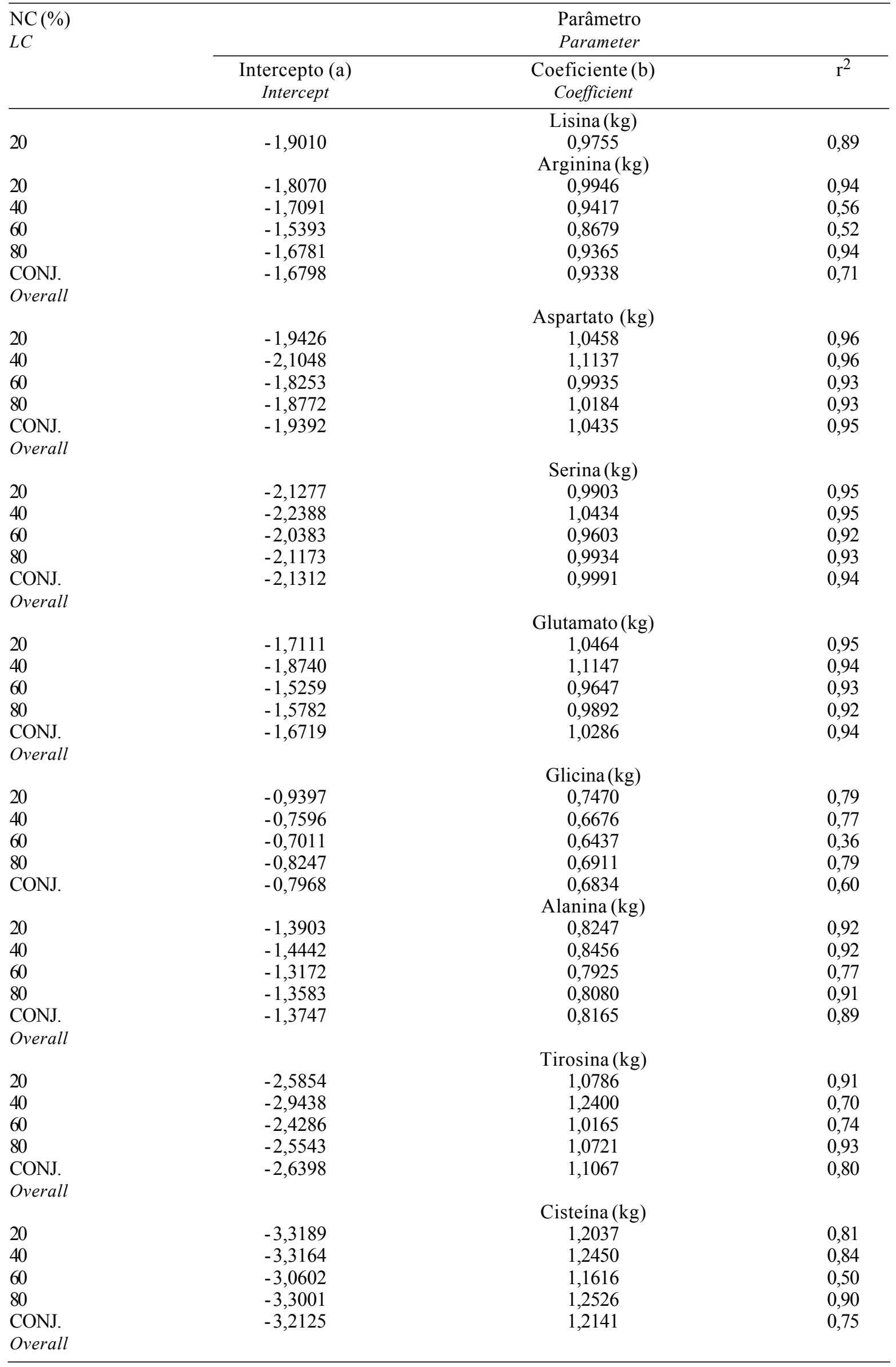


Tabela 5 - Exigências líquidas de aminoácidos para ganho (g/kg de GPCVZ), de bovinos Nelore, em função do peso vivo (PV), calculadas pelo método de equações

Table 5 - Amino acids net requirements for gain (g/kg EBWG), of Nellore bulls, in function of live weight (LW), calculated by the equations method

\begin{tabular}{|c|c|c|c|c|c|c|}
\hline \multirow{3}{*}{$\begin{array}{l}\mathrm{PV}(\mathrm{kg}) \\
L W(\mathrm{~kg})\end{array}$} & 200 & 250 & 300 & 350 & 400 & 450 \\
\hline & & & & & & \\
\hline & \multicolumn{6}{|c|}{$\begin{array}{l}\text { Exigência líquida } \\
\text { Net requirements }\end{array}$} \\
\hline$\overline{\text { Lys }}$ & 11,16 & 11,20 & 11,24 & 11,27 & 11,29 & 11,32 \\
\hline His & 4,74 & 4,99 & 5,21 & 5,40 & 5,57 & 5,72 \\
\hline Phe & 6,30 & 6,31 & 6,32 & 6,32 & 6,33 & 6,34 \\
\hline Thr & 6,78 & 6,87 & 6,95 & 7,02 & 7,08 & 7,13 \\
\hline Leu & 12,02 & 12,03 & 12,03 & 12,04 & 12,04 & 12,04 \\
\hline Ile & 5,51 & 5,58 & 5,64 & 5,69 & 5,73 & 5,76 \\
\hline Val & 7,66 & 7,59 & 7,53 & 7,48 & 7,44 & 7,41 \\
\hline Arg & 13,84 & 13,64 & 13,47 & 13,33 & 13,22 & 13,11 \\
\hline Asp & 15,05 & 15,19 & 15,32 & 15,42 & 15,51 & 15,59 \\
\hline Ser & 7,35 & 7,35 & 7,35 & 7,35 & 7,35 & 7,35 \\
\hline Glu & 25,40 & 25,56 & 25,69 & 25,81 & 25,90 & 25,99 \\
\hline Gly & 21,10 & 19,66 & 18,56 & 17,68 & 16,95 & 16,33 \\
\hline Ala & 13,30 & 12,77 & 12,35 & 12,00 & 11,71 & 11,46 \\
\hline Tyr & 4,41 & 4,52 & 4,61 & 4,68 & 4,75 & 4,81 \\
\hline Cys & 2,26 & 2,37 & 2,47 & 2,55 & 2,62 & 2,69 \\
\hline
\end{tabular}

$P C V Z=P V * 0,8975$.

gências metabolizáveis de aminoácidos para mantença, utilizando os fatores de utilização de 0,85 para metionina, lisina, histidina, fenilalanina, treonina e arginina e de 0,66 para leucina, isoleucina e valina, conforme sugerido por Evans \& Patterson (1985). Estas exigências, juntamente com as exigências de aminoácidos metabolizáveis para ganho, estão apresentadas na Tabela 6. Não existem dados sobre exigências de aminoácidos para zebuínos publicados na literatura consultada, até o momento, no Brasil.

Somando-se as exigências metabolizáveis para mantença e ganho, obtêm-se as exigências metabolizáveis totais, que estão apresentadas na Tabela 7, expressas em $\mathrm{g} / \mathrm{dia}$ e em porcentagem do total de aminoácidos essenciais. Merchen \& Titgemeyer (1992) estimaram as exigências de treonina, valina, metionina+cisteína, isoleucina, leucina, histidina, lisina, arginina, fenilalanina+tirosina e triptofano em 9,$14 ; 10,96$; 8,$05 ; 10,39 ; 16,01 ; 6,02 ; 16,52 ; 5,59 ; 15,09 ;$ e $2,26 \%$ do total de aminoácidos essenciais, respectivamente, para mantença e ganho de $1 \mathrm{~kg}$ de PV de um novilho de $250 \mathrm{~kg}$ de PV. Pode-se observar que estes valores estão relativamente próximos aos encontrados neste experimento, à exceção da arginina, que apresenta um valor bem acima do citado por Merchen \& Titgemeyer (1992).

Constam na Tabela 8 as exigências diárias totais de aminoácidos metabolizáveis, em g/dia, de um bovino de 250 a $450 \mathrm{~kg}$ de PV, com várias taxas de ganho. Nota-se uma diferença para a exigência de metionina do presente trabalho, por exemplo, para mantença $+1 \mathrm{~kg}$ de ganho de peso de um animal com $250 \mathrm{~kg}$ de PV (7,8 g/dia), comparada com os resultados de Wilkerson et al. (1993), que estimaram as exigências para mantença $+0,49 \mathrm{~kg}$ de ganho de uma novilho Holandês com o mesmo peso em 11,9 g/dia. Já Campbell et al. (1997), trabalhando com animais holandenses, obtiveram exigências diárias de metionina metabolizável de $8,4 \mathrm{~g}$ para animais com PV próximo de $200 \mathrm{~kg}$. As exigências de lisina, treonina, valina, isoleucina, leucina e fenilalanina encontram-se, também, inferiores aos valores encontrados por Wilkerson et al. (1993), mas proporcionalmente mais próximas. Esta diferença pode ser explicada em função das possíveis diferenças na composição corporal. Simpfendorfer (1974), citado por Ainslie et al. (1993), confere a animais da raça Holandesa, com PV próximo a $250 \mathrm{~kg}$, um corpo com teores de proteína e lipídios de 18,46 e 9,70\%, respectivamente. Os animais deste experimento apresenta- 
Tabela 6 - Exigências de aminoácidos metabolizáveis para mantença (AAMm) e para ganho (AAMg) de 1 kg de PCVZ (g/kg GPCVZ) de bovinos Nelore, em função do peso vivo (PV)

Table 6 - Metabolizable amino acids requirements for maintenance (MAAm) and gain (MAAg) of $1 \mathrm{~kg} E B W$ (g/kg EBWG) of Nellore bulls, in function of live weight (LW)

\begin{tabular}{|c|c|c|c|c|c|c|c|c|c|}
\hline $\begin{array}{l}\mathrm{PV}(\mathrm{kg}) \\
L W(\mathrm{~kg})\end{array}$ & Met & Lys & His & Phe & Thr & Leu & Ile & Val & Arg \\
\hline & \multicolumn{9}{|c|}{$\begin{array}{l}\text { AAMm } \\
\text { MAAm }\end{array}$} \\
\hline 200 & 1,48 & 8,31 & 3,34 & 4,83 & 5,33 & 12,22 & 5,54 & 7,92 & 10,66 \\
\hline 250 & 1,75 & 9,82 & 3,94 & 5,72 & 6,30 & 14,45 & 6,54 & 9,36 & 12,60 \\
\hline 300 & 2,01 & 11,26 & 4,52 & 6,55 & 7,23 & 16,57 & 7,50 & 10,73 & 14,45 \\
\hline 350 & 2,25 & 12,64 & 5,08 & 7,36 & 8,11 & 18,60 & 8,42 & 12,05 & 16,22 \\
\hline 400 & 2,49 & 13,98 & 5,61 & 8,13 & 8,97 & 20,55 & 9,31 & 13,32 & 17,93 \\
\hline \multirow[t]{2}{*}{450} & 2,72 & 15,27 & 6,13 & 8,88 & 9,79 & 22,45 & 10,17 & 14,55 & 19,58 \\
\hline & \multicolumn{9}{|c|}{$\begin{array}{c}\text { AAMg } \\
M A A g\end{array}$} \\
\hline 200 & 3,70 & 17,20 & 6,95 & 9,73 & 10,26 & 18,69 & 8,39 & 12,18 & 22,11 \\
\hline 250 & 4,76 & 18,40 & 7,43 & 10,41 & 10,98 & 19,99 & 8,98 & 13,03 & 23,65 \\
\hline 300 & 5,98 & 19,91 & 8,04 & 11,26 & 11,88 & 21,63 & 9,72 & 14,10 & 25,59 \\
\hline 350 & 7,44 & 21,79 & 8,80 & 12,33 & 13,00 & 23,67 & 10,63 & 15,43 & 28,00 \\
\hline 400 & 9,21 & 24,16 & 9,76 & 13,67 & 14,42 & 26,25 & 11,79 & 17,11 & 31,06 \\
\hline 450 & 11,44 & 27,22 & 10,99 & 15,40 & 16,24 & 29,58 & 13,29 & 19,28 & 34,99 \\
\hline
\end{tabular}

$P C V Z=P V * 0,8975$

Tabela 7 - Exigências totais de aminoácidos (mantença + ganho de $1 \mathrm{~kg}$ de PCVZ), expressas em g/dia e em \% do total de aminoácidos essenciais, de bovinos Nelore, em função do peso vivo (PV)

Table 7 - Total amino acids requirements (maintenance $+1 \mathrm{~kg}$ EBWG), in g/day and \% of total essential amino acids, of Nellore bulls, in function of live weight (LW)

\begin{tabular}{|c|c|c|c|c|c|c|c|c|c|}
\hline $\begin{array}{l}\mathrm{PV}(\mathrm{kg}) \\
L W(k g)\end{array}$ & Met & Lys & His & Phe & Thr & Leu & Ile & Val & Arg \\
\hline & \multicolumn{9}{|c|}{$\begin{array}{l}\text { g/dia } \\
\text { g/day }\end{array}$} \\
\hline 200 & 6,19 & 25,51 & 10,28 & 14,56 & 15,59 & 30,91 & 13,93 & 20,09 & 32,77 \\
\hline 250 & 7,31 & 28,22 & 11,37 & 16,13 & 17,28 & 34,44 & 15,53 & 22,39 & 36,25 \\
\hline 300 & 8,39 & 31,17 & 12,56 & 17,81 & 19,10 & 38,20 & 17,22 & 24,83 & 40,04 \\
\hline 350 & 9,42 & 34,43 & 13,87 & 19,68 & 21,11 & 42,27 & 19,06 & 27,47 & 44,22 \\
\hline 400 & 10,42 & 38,14 & 15,37 & 21,80 & 23,38 & 46,81 & 21,11 & 30,42 & 48,98 \\
\hline \multirow[t]{2}{*}{450} & 11,38 & 42,49 & 17,12 & 24,28 & 26,04 & 52,03 & 23,46 & 33,82 & 54,57 \\
\hline & \multicolumn{9}{|c|}{$\begin{array}{l}\% \text { aminoácidos essenciais } \\
\% \text { of total essential amino acids }\end{array}$} \\
\hline 200 & 3,64 & 15,17 & 6,11 & 8,66 & 9,27 & 18,38 & 8,29 & 11,95 & 19,49 \\
\hline 250 & 3,87 & 15,13 & 6,10 & 8,64 & 9,26 & 18,46 & 8,32 & 12,00 & 19,43 \\
\hline 300 & 4,01 & 15,10 & 6,09 & 8,63 & 9,26 & 18,51 & 8,34 & 12,03 & 19,40 \\
\hline 350 & 4,07 & 15,09 & 6,08 & 8,63 & 9,25 & 18,53 & 8,35 & 12,04 & 19,38 \\
\hline 400 & 4,06 & 15,09 & 6,08 & 8,63 & 9,25 & 18,52 & 8,35 & 12,04 & 19,38 \\
\hline 450 & 3,99 & 15,11 & 6,09 & 8,63 & 9,26 & 18,50 & 8,34 & 12,02 & 19,40 \\
\hline
\end{tabular}

$P C V Z=P V * 0,8975$.

ram, com este mesmo PV, teores corporais de proteína e de lipídios de 17,34 e 12,02\%, respectivamente. Notam-se menor teor de proteína e maior teor de gordura no corpo dos animais deste experimento, o que pode explicar a menor exigência de aminoácidos. As exigências de histidina encon- tram-se intermediárias aos valores encontrados por Zinn (1988) e Wilkerson et al. (1993) e a de arginina $(45,45 \mathrm{~g} / \mathrm{dia})$ apresentou um valor bem acima do relatado por Zinn (1988) (18,4 g/dia), para animais de $250 \mathrm{~kg}$ de $\mathrm{PV}$ e ganhando $1,5 \mathrm{~kg}$ de $\mathrm{PV} /$ dia. 
Tabela 8 - Exigências nutricionais de aminoácidos para animais Nelore não-castrados Table 8 - Amino acids nutritional requirements for Nellore bulls

\begin{tabular}{|c|c|c|c|c|c|c|c|c|c|c|}
\hline \multirow[b]{2}{*}{$\begin{array}{l}\mathrm{PV}(\mathrm{kg}) \\
L W(\mathrm{~kg})\end{array}$} & \multirow[b]{2}{*}{$\begin{array}{l}\operatorname{GMD}(\mathrm{kg} / \mathrm{d}) \\
L W G(\mathrm{~kg} / \mathrm{d})\end{array}$} & \multicolumn{6}{|c|}{$\begin{array}{c}\text { Aminoácidos } \\
\text { Amino acids }\end{array}$} & \multirow[b]{2}{*}{ Ile } & \multirow[b]{2}{*}{ Val } & \multirow[b]{2}{*}{ Arg } \\
\hline & & Met & Lys & His & Phe & Thr & Leu & & & \\
\hline 250 & 0,5 & 3,77 & 15,79 & 6,35 & 9,09 & 9,86 & 20,93 & 9,46 & 13,58 & 20,27 \\
\hline 250 & 1,0 & 7,08 & 25,58 & 10,31 & 14,63 & 15,70 & 31,57 & 14,24 & 20,52 & 32,86 \\
\hline 250 & 1,5 & 10,40 & 35,38 & 14,26 & 20,17 & 21,55 & 42,21 & 19,02 & 27,45 & 45,45 \\
\hline 250 & 2,0 & 13,72 & 45,17 & 18,22 & 25,71 & 27,39 & 52,86 & 23,80 & 34,39 & 58,03 \\
\hline 300 & 0,5 & 4,22 & 17,80 & 7,16 & 10,25 & 21,28 & 23,67 & 10,69 & 15,36 & 22,85 \\
\hline 300 & 1,0 & 7,85 & 28,54 & 11,50 & 16,32 & 29,79 & 35,33 & 15,94 & 22,96 & 36,65 \\
\hline 300 & 1,5 & 11,49 & 39,27 & 15,83 & 22,40 & 23,94 & 47,00 & 21,18 & 30,56 & 50,45 \\
\hline 300 & 2,0 & 15,12 & 50,01 & 20,17 & 28,47 & 30,35 & 58,67 & 26,42 & 38,17 & 64,25 \\
\hline 350 & 0,5 & 4,70 & 19,87 & 8,00 & 11,45 & 12,43 & 26,45 & 11,95 & 17,17 & 25,51 \\
\hline 350 & 1,0 & 8,72 & 31,76 & 12,79 & 18,17 & 19,52 & 39,36 & 17,75 & 25,58 & 40,79 \\
\hline 350 & 1,5 & 12,75 & 43,64 & 17,59 & 24,89 & 26,61 & 52,28 & 23,55 & 33,99 & 56,06 \\
\hline 350 & 2,0 & 16,77 & 55,52 & 22,39 & 31,62 & 33,70 & 65,19 & 29,36 & 42,41 & 71,34 \\
\hline 400 & 0,5 & 5,23 & 22,07 & 8,88 & 12,71 & 13,79 & 29,35 & 13,26 & 19,05 & 28,33 \\
\hline 400 & 1,0 & 9,73 & 35,37 & 14,25 & 20,24 & 21,73 & 43,81 & 19,76 & 28,47 & 45,43 \\
\hline 400 & 1,5 & 14,24 & 48,68 & 19,62 & 27,76 & 29,67 & 58,26 & 26,25 & 37,89 & 62,54 \\
\hline 400 & 2,0 & 18,74 & 61,99 & 25,00 & 35,29 & 37,61 & 72,72 & 32,75 & 47,31 & 79,64 \\
\hline 450 & 0,5 & 5,83 & 24,46 & 9,84 & 14,08 & 15,28 & 32,44 & 14,66 & 21,05 & 31,40 \\
\hline 450 & 1,0 & 10,95 & 39,58 & 15,94 & 22,63 & 24,30 & 48,87 & 22,04 & 31,76 & 50,83 \\
\hline 450 & 1,5 & 16,07 & 54,69 & 22,05 & 31,19 & 33,32 & 65,30 & 29,42 & 42,46 & 70,26 \\
\hline 450 & 2,0 & 21,19 & 69,81 & 28,16 & 39,74 & 42,34 & 81,73 & 36,80 & 53,17 & 89,70 \\
\hline
\end{tabular}

\section{Conclusões}

As exigências líquidas de metionina, lisina, histidina, fenilalanina, treonina, leucina, isoleucina, valina e arginina para ganho de $1 \mathrm{~kg}$ de peso vivo de animais da raça Nelore com $350 \mathrm{~kg}$ de peso vivo foram de 3,$54 ; 10,36 ; 4,19 ; 5,87 ; 6,19 ; 11,27 ; 5,06$; 7,34; e 13,33 g/dia.

As exigências totais de aminoácidos metabolizáveis, expressas em porcentagem do total de aminoácidos essenciais, apresentam pouca variação com o aumento do peso vivo, sendo os valores médios de 3,$94 ; 15,11 ; 6,09 ; 8,64 ; 9,26 ; 18,48 ; 8,33$; 12,01 ; e 19,41 para metionina, lisina, histidina, fenilalanina, treonina, leucina, isoleucina, valina e arginina, respectivamente.

\section{Literatura Citada}

AGRICULTURAL AND FOOD RESEARCH COUNCIL AFRC. Energy and protein requeriments of ruminants. Wallingford: Commonwealth Agricultural Bureaux International, 1993. 159p.

AINSLIE, S.J.; FOX, D.G.; PERRY, T.C. et al. Predicting amino acid adequacy of diets fed to Holstein steers. Journal of Animal Science, v.71, p.1312-1319, 1993.
CAMPBELL, C.G.; TITGEMEYER, E.C.; ST-JEAN, G. Sulfur amino acid utilization by growing steers. Journal of Animal Science, v.75, p.230-238, 1997.

EVANS, E.H.; PATTERSON, R.J. Use of dynamic modeling seen as good way to formulate crude protein, amino acid requirements for cattle diets. Feedstuffs, v.57, n.42, p.24-26, 1985.

HANSKINS, O.G.; HOWE, P.E. Estimation of the composition of beef carcasses and cuts. s.e. USDA (Thecnical BulletinUSDA, 926), 1946.

ÍTAVO, L.C.V. Consumo, digestibilidade e eficiência microbiana de novilhos alimentados com 20, 40, 60 e $80 \%$ de concentrado. Viçosa, MG: Universidade Federal de Viçosa, 2001. 116p. Tese (Doutorado em Zootecnia) - Universidade Federal de Viçosa, 2001.

LICITRA, G.; HERNANDEZ, T.M.; Van SOEST, J.P. Standardiztion of procedures for nitrogen fractionation of ruminants feeds. Animal Feed Science and Technology, v.57, n.4, p.347-358, 1996.

MERCHEN, N.R.; TITGEMEYER, E.C. Manipulation of amino acid supply to the growing ruminant. Journal of Animal Science, v.70, p.3238-3247, 1992.

NATIONAL RESEARCH COUNCIL - NRC. Nutrients requirements of beef cattle. 7.ed. Washington, D.C: 1996.242p.

O'CONNOR, J.D.; SNIFFEN, C.J.; FOX, D.G. et al. A net carbohydrate and protein system for evaluating cattle diets. IV - Predicting amino acid adequacy. Journal of Animal Science, v.71, p.1298-1311, 1993.

REGAZZI, J.A. Teste para verificar a identidade de modelos de regressão. Pesquisa Agropecuária Brasileira, v.31, n.1, p.1-17, 1996. 
RICHARDSON, C.R.; HATFIELD, E.E. The limiting amino acids in growing cattle. Journal of Animal Science, v.46, p.740-748, 1978.

RODRIGUEZ, N.M. Exigências em aminoácidos para vacas de alta produção. In: SIMPÓSIO LATINO-AMERICANO DE NUTRIÇÀO ANIMAL E SEMINARIO SOBRE TECNOLOGÍA DA PRODUÇÃO DE RAÇÕES, 1996, Campinas. Anais... Campinas: Colégio Brasileiro de Nutrição Animal, 1996. p.102-137.

RUSSEL, J.B.; O'CONNOR, J.D.; FOX, D.G. et al. A net carbohydrate and protein system for evaluating cattle diets. I. Rumen fermentation. Journal of Animal Science, v.70, n.11, p.3551-3561, 1992.

SILVA, D.J. Análise de alimentos (métodos químicos e biológicos). Viçosa, MG: Universidade Federal de Viçosa, 1990. 165p.

SILVA, F.F. Desempenho, características de carcaça, composição corporal e exigências nutricionais (de energia, proteína, aminoácidos e macrominerais) de novilhos Nelore, nas fases de recria e engorda, recebendo diferentes níveis de concentrado e proteína. Viçosa, MG: Universidade Federal de Viçosa, 2001, 211p. Tese (Doutorado em Zootecnia) - Universidade Federal de Viçosa, 2001.

SNIFFEN, C.J.; O'CONNOR, J.D.; Van SOEST, P.J. et al. A net carbohydrate and protein system for evaluating cattle diets. II - Carbohydrate and protein availability. Journal of Animal Science, v.70, n.11, p.3562-3577, 1992.
STORM, E.; ORSKOV, E.R. The nutritive value of rumen microorganisms in ruminants. 4 . The limiting amino acids of microbial protein in growing sheep determined by a new approach. British Journal of Nutrition, v.52, p.613-621, 1984.

VALADARES FILHO, S.C. Digestão pós-ruminal de proteína e exigências de aminoácidos para ruminantes. In: SIMPÓSIO INTERNACIONAL DE DIGESTIBILIDADE EM RUMINANTES. Anais... Lavras: Universidade Federal de Lavras, 1997. p.87-114, 1993.

WILKERSON, V.A.; KLOPFENSTEIN, T.J.; BRITTON, R.A. et al. Metabolizable protein and amino acid requirements of growing cattle. Journal of Animal Science, v.71, p.2777-2784, 1993.

ZINN, R.A. Crude protein and amino acid requirements of growing-finishing Holtein steers gaining 1,43 kilograms per day. Journal of Animal Science, v.66, p.1755-1763, 1988.

Recebido em: 29/05/01

Aceito em: 28/11/01 